\title{
In vitro Bovine Ciliary Body/Epithelium in a Small Continuously Perfused Ussing Type Chamber
}

\author{
Chi-Ho To ${ }^{1 \dagger}$, Kwok-Hei Mok ${ }^{1}$, Siu-Kee Tse ${ }^{1}$, Wing-Tak Siu ${ }^{1}$, Michel Millodot ${ }^{1}$, Kam-Len Lee ${ }^{2}$, and \\ Stuart Hodson ${ }^{3}$ \\ ${ }^{1}$ Laboratory of Ocular Physiology and Biochemistry, The Department of Optometry and Radiography, The \\ Hong Kong Polytechnic University, Hung Hom, Hong Kong, ${ }^{2}$ Department of Applied Biology and Chemical \\ Technology, The Hong Kong Polytechnic University, Hung Hom, Hong Kong, and ${ }^{3}$ Department of Optomet- \\ ry and Vision Sciences, University of Wales Cardiff, Cardiff, United Kingdonm.
}

Key words: ascorbate transport/ciliary body/ciliary epithelium/ouabain/Ussing-Zerahn chamber

\begin{abstract}
$A B S T R A C T$. Our goal is to assess the viability of an in vitro preparation of bovine ciliary body/epithelium (CBE) in a small volume Ussing-type chamber. A new small volume Ussing-type chamber with continuous perfusion was developed for bovine CBE. The trans-CBE electrical parameters were monitored and the electrical responses of the $\mathrm{CBE}$ to ouabain $(1$ and $0.01 \mathrm{mM})$ were recorded. The trans-CBE fluxes of $\left[{ }^{14} \mathrm{C}\right]-\mathrm{L}$-ascorbate and $\left[{ }^{3} \mathrm{H}\right]-\mathrm{L}$-glucose were also studied. The bovine $\mathrm{CBE}$ preparation was stable inside the chamber in terms of its potential difference (PD), short circuit current (SCC) and trans-CBE resistance. They were $-0.51 \pm 0.05 \mathrm{mV}$ (aqueous side negative), $-5.43 \pm 0.04 \mu \mathrm{Acm}^{-2}$ and $94 \pm 2 \Omega . \mathrm{cm}^{2}$ (mean \pm s.e.m., $\mathrm{n}=35$ ), respectively. The preparation hyperpolarised when $0.01 \mathrm{mM}$ ouabain was administered to the aqueous side, depolarised when ouabain was applied to the stromal side. $\left[{ }^{3} \mathrm{H}\right]-\mathrm{L}$-glucose diffusion was about $74 \mathrm{nEq} \mathbf{h}^{-1} \mathbf{c m}^{-2}$ in either direction $(n=12)$. Taking the area magnification factor of the $C B E$ into consideration, the diffusional L-glucose flux across the bovine CBE was comparable to other tight epithelia. A significant net ascorbate flux $(0.26 \pm 0.05 \mathrm{nEq}$ $\left.h^{-1} \mathrm{~cm}^{-2}, \mathrm{n}=4, \mathrm{p}<0.01\right)$ was found in the stroma to aqueous direction. We have developed a viable in vitro bovine CBE preparation which was (1) electrically stable, (2) responsive to ouabain, (3) tight to L-glucose diffusion, and (4) capable of actively secreting ascorbate. A net trans-CBE chloride transport $(0.81 \pm 0.30 \mu E q$ $\mathrm{h}^{-1} \mathrm{~cm}^{-2}, \mathrm{n}=12, \mathrm{p}=0.01$ ) from stromal to aqueous side was found in the present in vitro model under short-circuited conditions.
\end{abstract}

The aqueous humour is important for the normal functioning of the eye. It not only supplies nutrients to the avascular crystalline lens and cornea but also maintains the intraocular pressure of the eye which is crucial for the optical system to function. An abnormally high intraocular pressure is frequently associated with the sight threatening eye disease, glaucoma (6).

It is widely believed that a component of the aqueous humour is actively secreted by the ciliary epithelium of the ciliary body (4). The bilayer ciliary epithelium is composed of non-pigmented (NPE) and pigmented (PE) ciliary epithelial cells which form a functional syncytium which produces the aqueous humour. However, the ionic mechanism behind the production of aqueous humour is not fully understood.

It is generally accepted that fluid secretion is driven by active transport of ions. The active ion flow creates

\footnotetext{
$\dagger$ To whom correspondence should be addressed.

Tel: +85-2-27666102, Fax: +85-2-27646051

E-mail: Orchto@Polyu.edu.hk
}

an osmotic gradient by which bulk flow of water follows. Therefore in order to understand how aqueous humour is produced, it is important to identify any active ion transport across the ciliary epithelium.

Electrophysiological techniques with Ussing-Zerahn type chambers aim to understand mechanisms of ion or substrate transport across cells and epithelia. Isolated mammalian iris ciliary body/epithelium preparations have been mounted in Ussing-type chambers previously $(3,8)$. Based on the positive polarity of the bovine ciliary epithelium on the aqueous side in $\mathrm{HCO}_{3}$-free medium, Cole (1962) suggested that sodium ion transport was responsible for aqueous humour production. However, later mammalian studies employed $\mathrm{CO}_{2}$ perfusion and showed that most ciliary body preparations demonstrate a negative potential on the aqueous side (2, 8) suggesting a net anionic rather than cationic transport.

Trans-ciliary epithelial ion transport has been mostly studied with modified Ussing chambers and early results with cat iris-ciliary body preparations have shown 
that chloride ion was actively transported from the blood to the aqueous side (8). Kishida and colleagues (1982) have also demonstrated an active chloride transport across the isolated rabbit iris ciliary body with high bicarbonate $(115 \mathrm{mM})$ bathing solution. However, other workers have been unable to reproduce these results (2). The reason for the discrepancy between these studies was not clear although the technical difficulty in mounting viable in vitro ciliary body/epithelium prepartions is well known. Although recent studies on the ion channels with patch clamping have provided important information on the transmembrane events of the ciliary epithelium (10), active transcellular ion transport across the CBE has yet to be conclusively demonstrated.

In the present study, we established an alternative mammalian model to rabbit which may be beneficial in shedding new light on the mechanism of aqueous humour production. Bovine tissue is easier to work with given that it is relatively large and readily available. We have assessed the viability of the in vitro bovine CBE preparation in terms of (1) the stability of the transepithelial electrical PD, SCC (short circuit current) and trans-CBE resistance; (2) the action of ouabain on the preparation; (3) leakiness of the preparation based on the measurement of $\left[{ }^{3} \mathrm{H}\right]-\mathrm{L}$-glucose flux, and (4) active transport of $\left[{ }^{14} \mathrm{C}\right]-\mathrm{L}$-ascorbate. With the chamber, we also studied the sodium and chloride ion fluxes under short circuited conditions.

\section{MATERIALS AND METHODS}

Unless otherwise stated, all chemicals were purchased from Sigma Chemical Limited (USA).

\section{A. Dissection of bovine CBE preparations}

Fresh bovine eyes were obtained from a local abattoir within about 90 minutes of sacrifice. The eyes were kept at $4^{\circ} \mathrm{C}$ on ice during transport to the laboratory. The extraocular muscles and fat were trimmed from the eye. The cornea was removed by cutting at the limbus with a razor blade and scissors. Two incisions were made in the eye at right angles to each other so that the iris was dissected into four quarters. The anterior lens capsule was dissected into quarters along with the iris. The lens capsule attaches strongly to the ciliary body. It was gently lifted from the lens cortex and acted as a 'handle' for holding the preparation in later manipulation. Posteriorly, the cuts were extended to the equatorial plane of the eye and into the vitreous. The ciliary body was carefully dissected away from the sclera at the anterior angle, and the ciliary body was detached from the sclera. The vitreous attachments to the ciliary body were carefully removed using scissors. A sector of ciliary body (which formed the CBE preparation) was then dissected away at the equatorial plane (Figs. 1(a) and (b)), and was ready to be mounted in the chamber. (a)

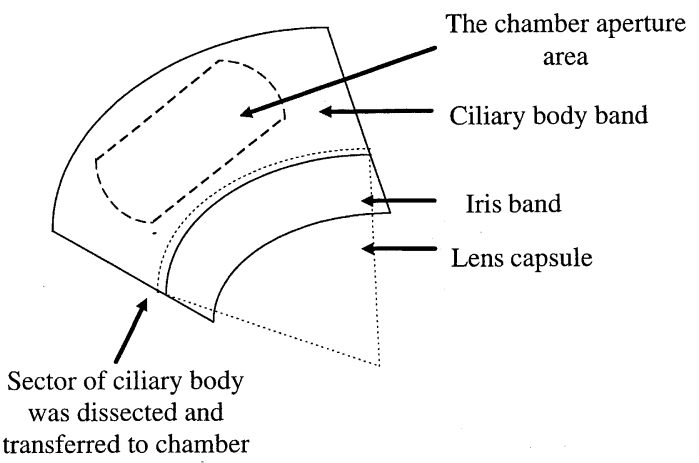

(b)

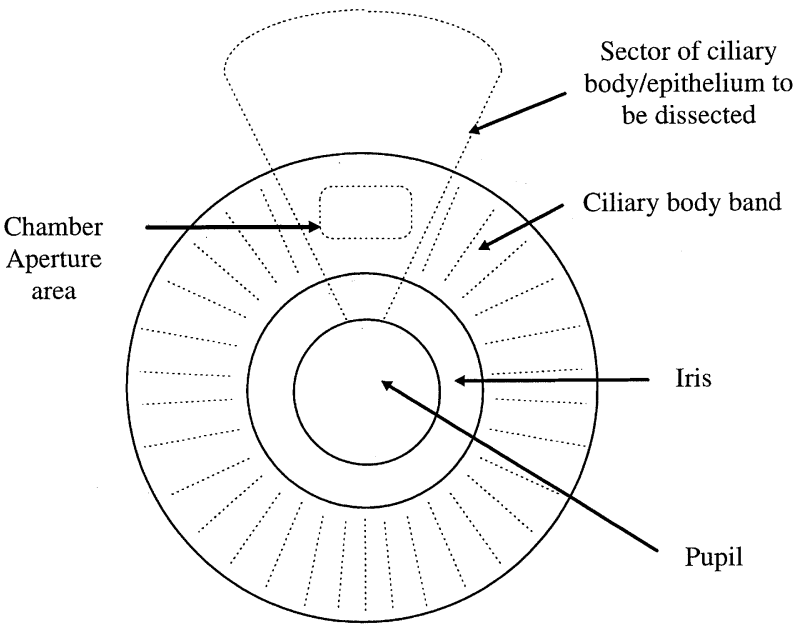

Fig. 1. (a) Isolated ciliary body sector showing the chamber aperture area, (b) the isolated CBE preparation with respect to the whole ciliary body (view from the posterior segment).

\section{B. In vitro iris-ciliary body preparation in Ussing-type chamber}

The design of the Ussing-type chamber for ciliary body is shown in Figure 2. It differs from the classical design of the Ussing chamber in that the volume of each half chamber is small (half chamber volume: $0.125 \mathrm{ml}$ ). The perfusion inlet is close to the preparation so that fresh perfusate can be delivered close to the tissues. Thus it does not require bubbling of gases to promote stirring as in the traditional Ussing chamber (8). The entire half chamber is completely separated from the atmosphere. The chamber cavity is rectangular in shape. The flat surface area of the cavity is estimated to be 0.25 $\mathrm{cm}^{2}$, and the depth is $0.5 \mathrm{~cm}$.

The isolated CBE preparation was transferred into the Ussing chamber, and positioned so that the middle part of the CBE was clamped as the exposed area inside the chamber. The iris was not included in the in vitro preparation (Fig. 2).

The two half chambers were closed and clamped together using four screws and wing nuts at the four corners. The tissue was sealed with a rubber disc which surrounded the chamber cavity to prevent leakage of perfusates. The cham- 


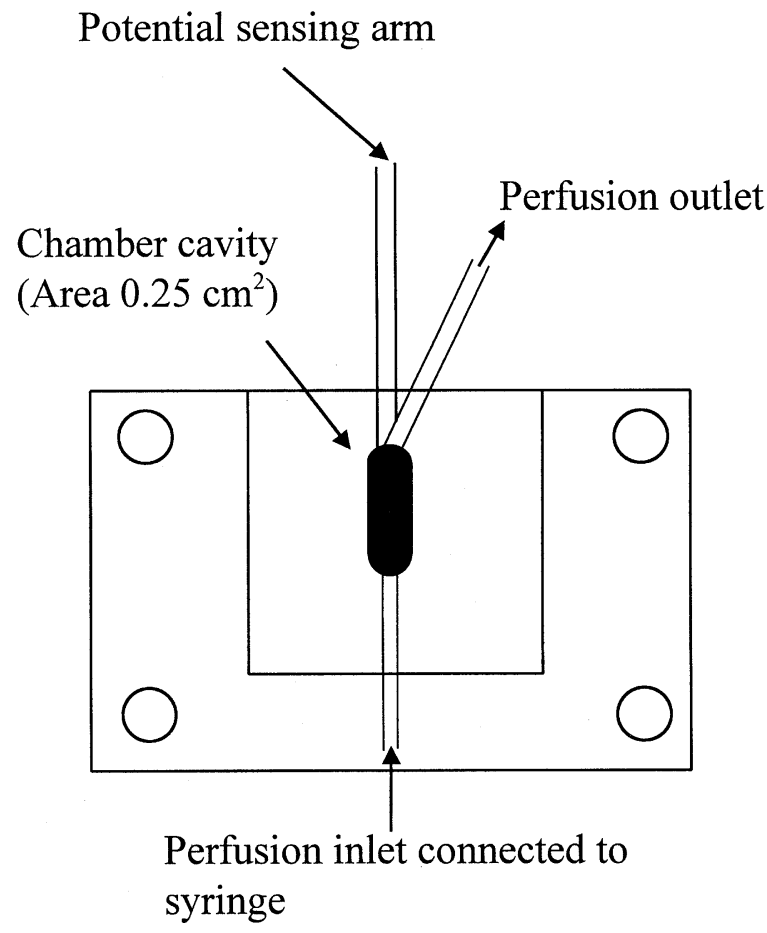

Front view of the half chamber

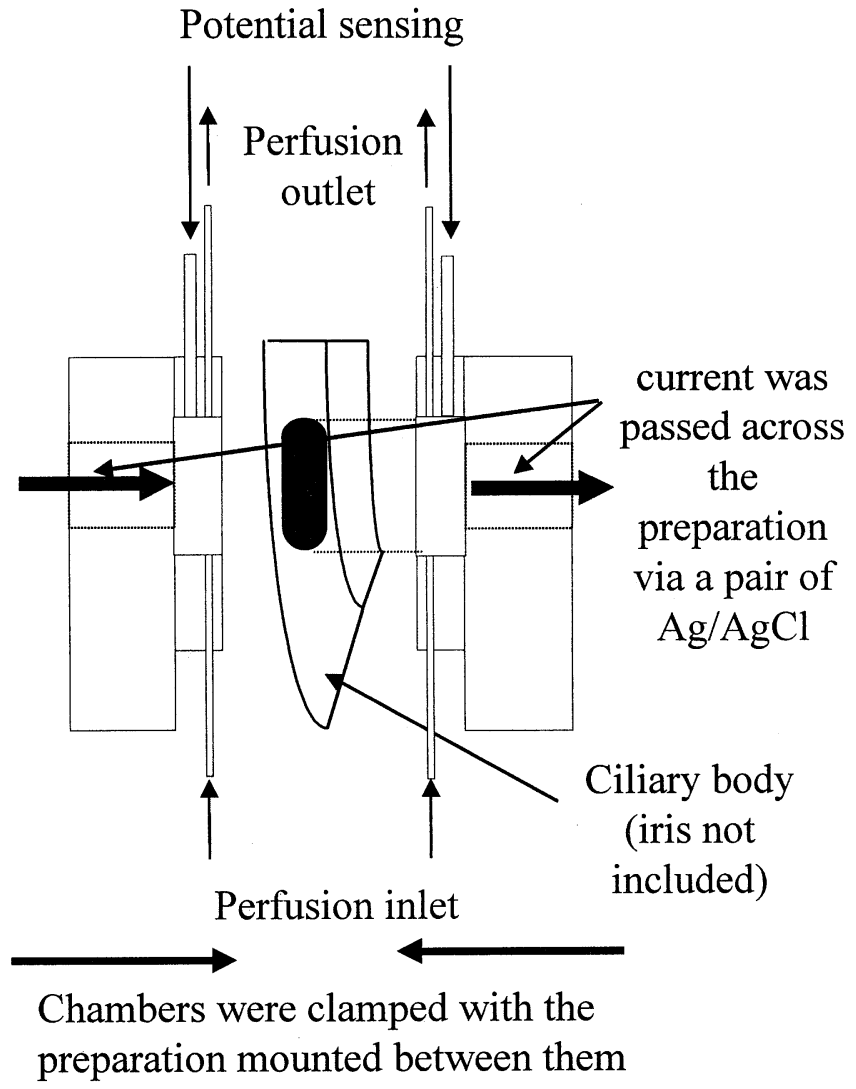

Lateral view of assembled chamber

Fig. 2. The modified small volume Ussing-type chamber for bovine CBE preparation.

ber was continuously perfused with balanced Ringer solution at $35^{\circ} \mathrm{C}$ through the perfusion inlets and outlets (polyethylene tubing) by a digital infusion pump (Cole Parmer Instrument Ltd., USA) at $10 \mathrm{ml} \mathrm{h}^{-1}$. The perfusates from the outlets were either continuously drained to a beaker during the equilibration time or collected in scintillation vials for counting purposes. The average turn-over time of solution per half chamber was about 45 seconds, i.e. 1.33 chamber fraction was cleared per min (chamber volume of $0.125 \mathrm{~cm}^{3}$ and the perfusion rate of $10 \mathrm{ml} \mathrm{h}^{-1}$ ). The composition of the Ringer solution was $113 \mathrm{mM} \mathrm{NaCl}, 4.56 \mathrm{mM} \mathrm{KCl}, 21 \mathrm{mM} \mathrm{NaHCO}, 0.6$ $\mathrm{mM} \mathrm{MgSO}_{4}, 7.5 \mathrm{mM}$ glucose, $1 \mathrm{mM}$ reduced glutathione, 1.4 $\mathrm{mM} \mathrm{CaCl}, 1 \mathrm{mM} \mathrm{Na} \mathrm{HPO}_{4}, 10 \mathrm{mM}$ HEPES with $\mathrm{pH}$ adjusted to 7.4. The Ringer solution was bubbled with $20 \% \mathrm{O}_{2}$, $5 \% \mathrm{CO}_{2}$, and $75 \% \mathrm{~N}_{2}$ before use. The $\mathrm{pH}$ of the perfusate collected from the chamber was constant throughout the duration of flux experiment. The Ringer solution was maintained at $35^{\circ} \mathrm{C}$ by prewarming with a d.c. heating coil, which also wrapped around the whole chamber during perfusion. The temperature of the perfusate was maintained at $35^{\circ} \mathrm{C}$.
The PD generated across the preparation was measured with two silver-silver chloride electrodes which were fed into a voltage and current clamp (DVC-1000, World Precision Instrument, USA) via the potential sensing arms. A current (10 $\mu \mathrm{A})$ was periodically passed through another pair of $\mathrm{Ag} / \mathrm{AgCl}$ electrodes, one in each half chamber to measure the fluid or blank resistance plus the tissue resistance. By subtracting the fluid resistance of the chamber without the preparation from the total resistance, the trans-CBE resistance was obtained. The SCC was then calculated from the potential difference and the trans-CBE resistance. Any potential drift between the $\mathrm{Ag} / \mathrm{AgCl}$ electrodes was corrected regularly using a by-pass arm between them.

\section{Ascorbate, glucose, chloride and sodium transport ex- periments}

$\left[{ }^{3} \mathrm{H}\right]$-L-glucose was purchased from Sigma (USA). $\left[{ }^{14} \mathrm{C}\right]-\mathrm{L}-$ ascorbic acid, $\left[{ }^{22} \mathrm{Na}\right]$ and $\left[{ }^{36} \mathrm{Cl}\right]$ were purchased from Amersham (UK).

In the ascorbate transport experiments, $0.05 \mathrm{mM}$ unlabel- 
led ascorbic acid and $0.5 \mathrm{mM}$ thiourea were added to the normal Ringer solution. The thiourea was added to prevent oxidation of ascorbate (1). Ascorbic acid and thiourea were purchased from Riedel-de Haën AG (Germany). [ $\left.{ }^{14} \mathrm{C}\right]-\mathrm{L}-a$ ascorbic acid and $\left[{ }^{3} \mathrm{H}\right]$-L-glucose were dissolved in the loading solution for flux measurement. Sodium and chloride ion fluxes were studied by means of dual-label experiments where they can be measured simultaneously in one experiment. The emission spectra of the two ions can be separated by using different counting windows and by counting different concentrations of radiolabels as control. The preparation was continuously perfused with Ringer solution while the perfusates from the two half chambers were continuously and separately collected with pairs of scintillation vials designated for each half chamber. Two $\mathrm{ml}$ of perfusates were collected every $12 \mathrm{~min}$ into scintillation vials, each containing $15 \mathrm{ml}$ scintillation cocktail (NBCS104, from Amersham, UK). Five pairs of perfusates in vials can be collected per hour and so on. Care was taken so that the last drop of perfusate dripped into the vials by gently touching the perfusion outlet against the inner wall of the vials. The outlets were then quickly transferred to new vials for the continuous collection of the perfusates. A number of perfusates from the loading and collecting sides as a function of time were thus gathered. Before loading radioisotopes into the chamber, the preparation was perfused with cold Ringer solution and three samples of $2 \mathrm{ml}$ perfusate (background count) were collected from each side with $20 \mathrm{ml}$ vials (Wheaton, USA). The vials were counted in a Liquid Scintillation Counter (Beckman 1000, USA). The ion flux experiments were performed only if the background counts were stable.

Unidirectional inward (stroma to aqueous) and outward (aqueous to stroma) $\left[{ }^{14} \mathrm{C}\right]-\mathrm{L}$-ascorbate, $\left[{ }^{3} \mathrm{H}\right]-\mathrm{L}$-glucose, ${ }^{22} \mathrm{Na}$ and ${ }^{36} \mathrm{Cl}$ fluxes were measured while the preparations were continuously short-circuited. Radioisotopes were continuously perfused to one side (stromal or aqueous) of the preparation, while the other side was perfused with the Ringer solution. The half chamber to be loaded with radioisotopes was called the loading side whereas the other half chamber was called the collecting side. After a series of preliminary experiments, it was found that the radioactivity of the collecting side increased with time and it reached a plateau after about 90 minutes. Therefore in subsequent experiments, 90 minutes of equilibration period lapsed before starting the continuous collection of perfusates. Perfusates were then collected from both sides and were counted immediately. Three or more consecutive samples were sampled until they gave similar stable counts. The data were then averaged and used in calculating the unidirectional flux. The unidirectional flux was calculated using the equation:

$$
J=\frac{\frac{C}{L} \cdot[i] \cdot V}{t \cdot A}
$$

$J=$ Unidirectional flux
$L=$ Radioactivity of the perfusate from the loading side in cpm (counts per minute) per vial

$C=$ Radioactivity of the perfusate from the collecting side in cpm per vial collected in pair with the loading solution (i.e. both were collected at the same time interval)

$A=$ Aperture area of the chamber

$t=$ Collection duration

$[i]=$ Concentration of the chemical in the Ringer solution

$V=$ Volume of perfusate collected per vial

The results were expressed as mean \pm s.e.m. The difference between the means of the unidirectional fluxes was evaluated using an unpaired Student's t-test (two-tailed p-value).

\section{RESULTS}

The trans-CBE electrical parameters

The potential generated by the $\mathrm{CB}$ preparations on the aqueous side was consistently negative. The average values of $\mathrm{PD}, \mathrm{SCC}$ and trans-CBE resistance were $-0.51 \pm 0.05 \mathrm{mV}, \quad-5.43 \pm 0.04 \mu \mathrm{Acm}^{-2}$ and $94 \pm 2$

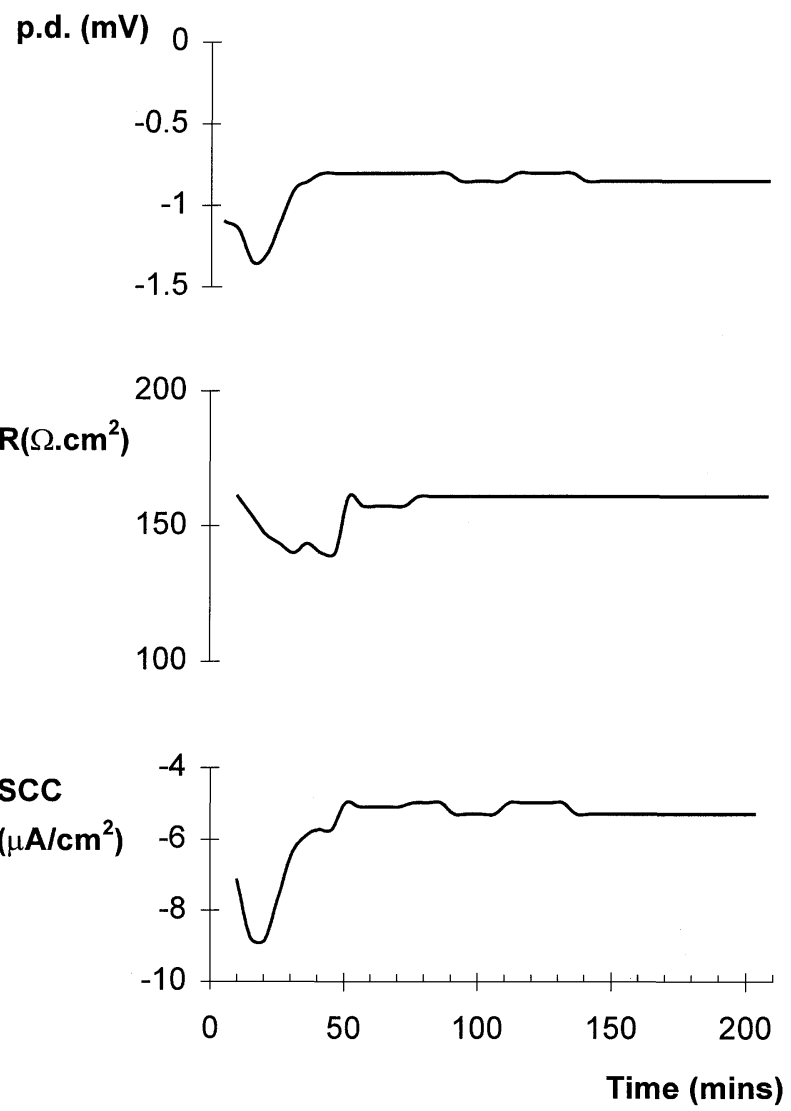

Fig. 3. Typical electrical potential, resistance and short circuit current of in vitro bovine $\mathrm{CBE}$ preparation. 
$\Omega . \mathrm{cm}^{2}$ (mean \pm s.e.m., $\mathrm{n}=35$ ) respectively. Typically the tissues were stable for four to five hours according to the $\mathrm{PD}, \mathrm{SCC}$, and trans-CBE resistance measurements (Fig. 3). Approximately $80 \%$ of the CBE preparations showed stable baseline electrical parameters.

\section{Ouabain application}

When $1 \mathrm{mM}$ ouabain was applied bilaterally, it hyperpolarized the preparations at first and caused a tran- sient increase in SCC. This was followed by depolarisation and the SCC decreased (Fig. 4(a)). The responses can be segregated at lower ouabain concentration $(0.01$ $\mathrm{mM}$ ). Application of $0.01 \mathrm{mM}$ ouabain at the aqueous side produced a sustained hyperpolarisation of the CBE. The SCC increased by $156 \pm 22 \%$ (mean \pm s.e.m, $\mathrm{n}=15$ ) from basal values. Stromal application caused a delayed but sustained depolarization and the SCC decreased by $64 \pm 6 \%$ (mean \pm s.e.m, $n=15$ ) (Fig. 4(b)).
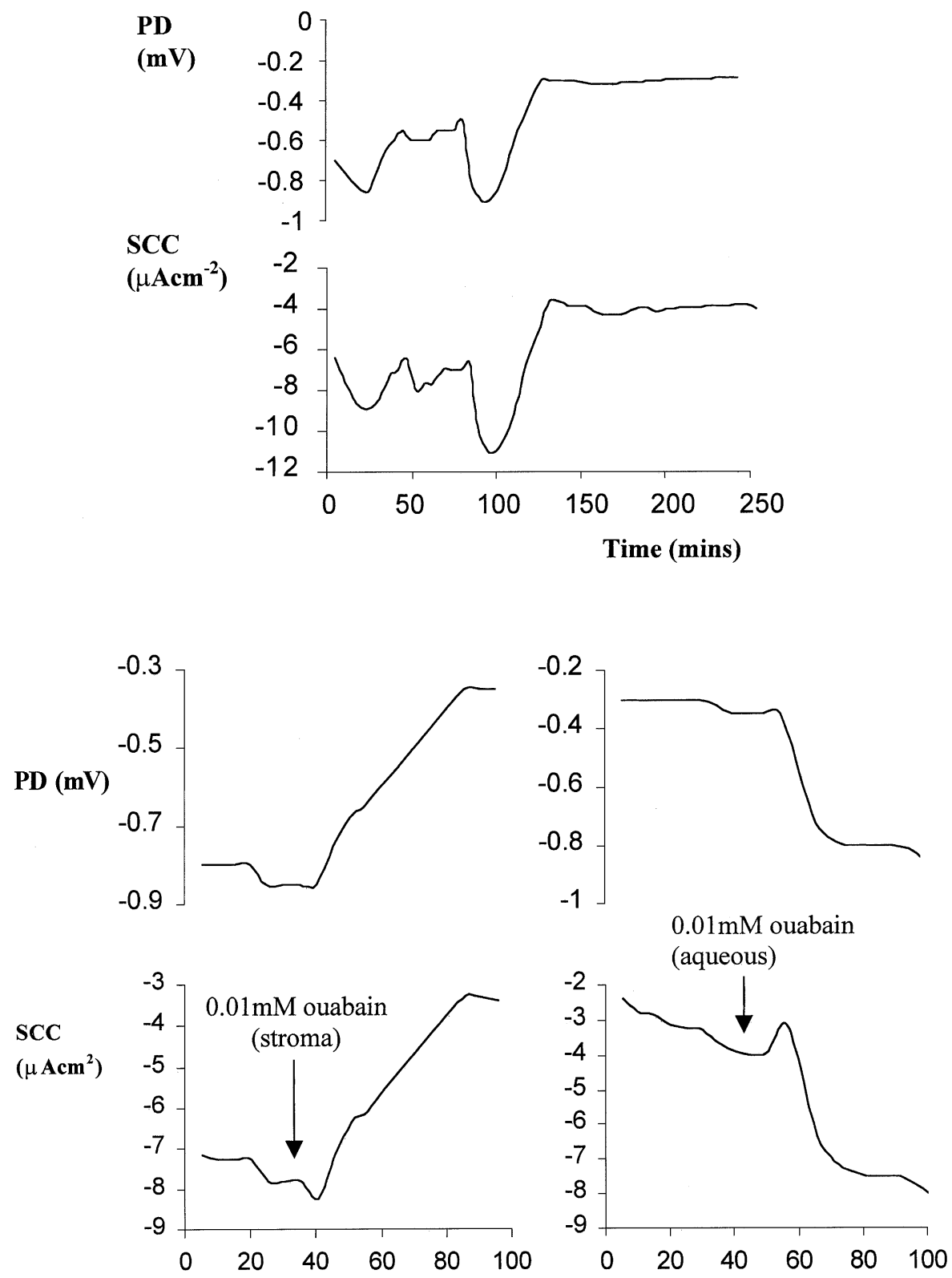

Time (mins)

Fig. 4. Typical effects of (a) bilateral application of $1 \mathrm{mM}$ ouabain, (b) aqueous or stromal application of $0.01 \mathrm{mM}$ ouabain on the in vitro bovine CBE preparation. 


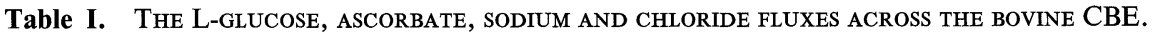

\begin{tabular}{|c|c|c|c|}
\hline Flux & $\begin{array}{c}\text { Inward } \\
J_{s a}\end{array}$ & $\begin{array}{c}\text { Outward } \\
J_{a s}\end{array}$ & $\begin{array}{c}\text { Net flux } \\
J_{s a}-J_{a s}\end{array}$ \\
\hline L-glucose $(n=12)$ & $\mathrm{nEq} \mathrm{h}^{-1} \mathrm{~cm}^{-2}$ & $72 \pm 13 \quad \mathrm{nEq} \mathrm{h}^{-1} \mathrm{~cm}^{-2}$ & not significant \\
\hline Ascorbate $(n=4)$ & $0.55 \pm 0.03 \mathrm{nEq} \mathrm{h}^{-1} \mathrm{~cm}^{-2}$ & $0.29 \pm 0.03 \mathrm{nEq} \mathrm{h}^{-1} \mathrm{~cm}^{-2}$ & $0.26 \pm 0.05 \mathrm{nEq} \mathrm{h}^{-1} \mathrm{~cm}^{-2}(\mathrm{p}<0.01)$ \\
\hline Sodium $\quad(n=12)$ & $11.7 \pm 0.3 \mu \mathrm{Eq} \mathrm{h}^{-1} \mathrm{~cm}^{-2}$ & $11.7 \pm 0.6 \mu \mathrm{Eq} \mathrm{h}^{-1} \mathrm{~cm}^{-2}$ & not significant \\
\hline Chloride $(n=12)$ & $4.50 \pm 0.22 \mu \mathrm{Eq} \mathrm{h}^{-1} \mathrm{~cm}^{-2}$ & $3.69 \pm 0.21 \mu \mathrm{Eq} \mathrm{h}^{-1} \mathrm{~cm}^{-2}$ & $0.81 \pm 0.30 \mu \mathrm{Eq} \mathrm{h}^{-1} \mathrm{~cm}^{-2}(\mathrm{p}=0.01)$ \\
\hline
\end{tabular}

$J_{s a}$ is the unidirectional flux from stromal to aqueous side. $J_{a s}$ is the unidirectional flux from aqueous to stromal side. Data are expressed in mean \pm SEM.

The ouabain responses were consistent and irrespective of the basal values of the PD or SCC; i.e. aqueous ouabain always produced hyperpolarisation and stromal ouabain always depolarised the preparations. The preparations remained either hyperpolarized or depolarised for over 60 minutes.

\section{L-glucose, ascorbate, sodium and chloride fluxes across the bovine CBE}

The results were shown in Table I. All the fluxes stabilised after about 90 minutes of loading time. A statistically significant net ascorbate flux of $0.26 \pm 0.05$ $\mathrm{nEq} \mathrm{h} \mathrm{h}^{-1} \mathrm{~cm}^{-2}(\mathrm{n}=4, \mathrm{p}<0.01)$ was found in the stroma to aqueous or inward direction. L-glucose fluxes were similar in either direction as expected since it traverses the cell mainly via the paracellular pathway by simple diffusion. In the dual label experiments of chloride and sodium, there was no significant net sodium flux found in either direction. However, the chloride was found to be actively secreted from the stromal to aqueous side $\left(0.81 \pm 0.30 \mu \mathrm{mol} \mathrm{h}^{-1} \mathrm{~cm}^{-2}, \mathrm{p}=0.01\right)$.

\section{DISCUSSION}

\section{Chamber design}

Traditional Ussing chamber studies used the whole iris and ciliary body and it left a central pupillary aperture which was blocked eventually (12), and the iris-ciliary body formed the exposed area inside the chamber. We have devised a dissection technique by which a sector of the ciliary body was isolated. Since the iris does not play any known role in producing aqueous humour, it was not included as part of the in vitro preparation. The exposed area inside the chamber was exclusively CBE. This was confirmed microscopically after the preparation was removed from the chamber.

During the dissection, extreme care was taken not to damage the ciliary epithelium when the vitreous was separated from the preparation. The preparation was easy to handle because of its relatively large size and it showed good electrical stability inside the Ussing chamber. The average success rate in mounting stable CB preparations was high (about $80 \%$ ). The volume of our chamber cavity was small $(0.125 \mathrm{ml})$ and it was continu- ously perfused with fresh Ringer solution by a perfusion pump. It allowed rapid turnover rate of Ringer solution in each half chamber. Fresh nutrients can be continuously supplied to the preparation and metabolic wastes were quickly removed.

\section{Electrical parameters}

Cole (1962) reported the first electrophysiological study on bovine iris-ciliary body preparation and a positive standing PD was found at the aqueous side. However later studies with other mammalian ciliary body preparations found a negative PD across the preparation (2). It has been suggested that the lack of bicarbonate in the bathing solution may be the reason for this discrepancy (12) and that the electrical signal from the sensory retina may also have contributed to the PD (9), however the exact reason for the discrepancy remains unclear.

The PD of our CBE preparation was consistently negative at the aqueous side. Although the magnitudes of the PD, SCC and trans-CBE resistance were slightly lower than those of rabbits (12), cat (8) and dog (9), the electrical parameters were typically stable for three hours or longer in most experiments. Presumably only physiologically intact preparation will maintain stable resistance; we interpret the stable resistance recording and the $\mathrm{PD}$ reading to indicate good integrity and vitality of the in vitro preparation.

\section{Ouabain's action}

$\mathrm{Na} / \mathrm{K}$-ATPases are present in both NPE and PE, pumping sodium ions into the aqueous and ciliary stroma respectively (14). By selectively blocking the $\mathrm{Na} / \mathrm{K}$ ATPase in the NPE with lower ouabain concentration, the efflux of sodium ion into the aqueous decreased and the PD hyperpolarised. Similarly, when the $\mathrm{Na} / \mathrm{K}$ ATPase in PE was inhibited, the PD depolarised. The results were consistent with a dual $\mathrm{Na} / \mathrm{K}$-ATPase model $(12,14)$.

\section{L-glucose diffusion}

We used L-glucose to monitor the paracellular diffusional pathway. When there is no external osmotic or hydrostatic force, L-glucose is expected to diffuse 
across the ciliary epithelium from either direction at the same rate. This was true in our results. Mannitol was previously used as a diffusional control in an ion flux study across rabbit iris-ciliary body (2). Since L-glucose has similar molecular weight $(\mathrm{FW}=180.2)$ to mannitol $(\mathrm{FW}=182.2)$ and neither penetrates the cell membranes, L-glucose fluxes measured across the bovine CBE in this study can be compared with mannitol fluxes measured in other epithelia. The unidirectional L-glucose flux across the bovine CBE was about $74 \mathrm{nEq}$ $\mathrm{h}^{-1} \mathrm{~cm}^{-2}$ (calculated from a flat surface area of 0.25 $\mathrm{cm}^{2}$ ), and was similar to the mannitol flux of $72 \mathrm{nEq}$ $\mathrm{h}^{-1} \mathrm{~cm}^{-2}$ (calculated from a flat surface area of 0.75 $\mathrm{cm}^{2}$ ) across the isolated rabbit iris-ciliary body as reported by Chu and Candia (1987). Considering the extensive folding of the CBE, the true surface area of the CBE will be larger than the flat surface area. Therefore, calculation using the aperture flat surface area alone will show a higher unidirectional flux per unit area. A conversion factor which correlates the flat surface area of the chamber cavity to the true surface area of the ciliary body is needed. However, the value of the factor for the bovine ciliary body is unknown. The surface area of the ciliary processes in the rabbit has been estimated by Cole (1966) who reported that the degree of convolution was much greater at the tips than at the pars plana. He estimated the average conversion factor to be about 6.5. Assuming the extent of convolution is similar between ox and rabbit ciliary bodies, therefore, using Cole's factor, the area-corrected unidirectional Lglucose flux in this study is about $11.4 \mathrm{nEq} \mathrm{h}^{-1} \mathrm{~cm}^{-2}$. These data are similar to the mannitol fluxes in the other "tight" epithelia (5) and suggest that the bovine ciliary epithelium is a "tight" rather than "leaky" epithelium. Similar conclusions may be drawn by correcting the trans-CBE resistance with the conversion factor derived by Cole; the area-corrected resistance is about $570 \Omega \mathrm{cm}^{2}$. This calculated resistance also classifies the ciliary epithelium as a tight epithelium (7). Our data demonstrates that the in vitro preparation is capable of maintaining a low leakage high resistance barrier.

\section{Active ascorbate transport}

It is believed that ascorbate is actively secreted from the stroma to the aqueous humour (1) and the concentration of ascorbic acid in the aqueous humour of ox was also reported to be high ( $3 \mathrm{mM})(13)$. We have found a net ascorbate transport across the bovine CBE preparation. A similar finding has been reported for rabbit ciliary body preparation by Chu and Candia (1988). However, the ratio between inward: outward ascorbate flux was about 2:1 in our study compared to the ratio of 10:1 as reported by Chu and Candia (1988). The reason for this discrepancy is unclear although species differences may play a role. However, it is clear that our in vitro bovine ciliary body preparation was capable of actively transporting ascorbate.

\section{Chloride and sodium ion transport}

In our dual label experiments using chloride and sodium ions together, a net chloride but not sodium transport was found in the stromal to aqueous direction. This is the first trans-CBE active chloride transport reported in ox. Active sodium (3) and chloride transport (8) have been previously proposed to be the driving force for the fluid secretion. However, more recent study (2) has failed to identify any ion transport across the ciliary body/epithelium preparation under physiological conditions. Therefore, at present, the active ion transport mechanism behind the fluid production is still unknown. We suggested that the net chloride ion transport across the bovine CBE may play an important role in the secretion process of the aqueous humour of the eye.

We conclude that our in vitro bovine CBE preparation was viable judging from: (1) stable electrical parameters, (2) responses to ouabain at both NPE and PE, (3) the maintenance of a tight resistance barrier to Lglucose, and (4) the presence of active ascorbate transport. We have also demonstrated for the first time a net trans-CBE chloride flux in the bovine tissues, which may be the driving force for the aqueous humour formation. We propose that our in vitro bovine CBE preparation is a viable and valid model for characterising trans-CBE ion transport.

Acknowledgement. The work was supported by the Competitive Earmarked Research Grant of Research Grants Council/University Grants Committee (HKP13M/94), The Hong Kong Polytechnic University Internal Research Grants (351/108 \& 351/109) and Departmental Research Grants (350/508).

We thank Dr. Chris Wigham, Department of Optometry and Vision Sciences, University of Wales Cardiff, for his expert advice on the study.

\section{REFERENCES}

1. Chu, T.C. and CANDiA, O.A. 1988. Active transport of ascorbate across the isolated rabbit ciliary epithelium. Invest. Ophthalmol. Vis. Sci., 29(4): 594-599.

2. Chu, T.C., Candia, O.A., and Podos, S.M. 1987. Electrical parameters of the isolated monkey ciliary epithelium and effects of pharmacological agents. Invest. Ophthalmol. Vis. Sci., 28(10): 1644-1648.

3. Cole, D.F. 1962. Transport across the isolated ciliary body of ox and rabbit. Brit. J. Ophthalmol., 46: 577-591.

4. Cole, D.F. 1966. Aqueous humour formation. Doc. Ophthalmol., 21: 116-238.

5. Dawson, D.C. 1977. $\mathrm{Na}$ and $\mathrm{Cl}$ transport across the isolated turtle colon: parallel pathways for transmural ion movement. $J$. Memb. Biol., 37: 213-233.

6. Forrester, J., Dick, A., McMenamin, P., and Lee, W. 1996. The Eye - Basic Sciences in Practice. London: WB Saunders 
CO. Ltd.

7. Frömter, E. and DiAmond, J. 1972. Route of passive ion permeation in epithelia. Nature New Biology, 235: 9-13.

8. Holland, M.G. and GIPSON, C.C. 1970. Chloride ion transport in the isolated ciliary body. Invest. Ophthalmol. Vis. Sci. 9: $20-29$.

9. Iizuka, S., Kishida, K., Tsuboi, S., Emi, K., and Manabe, R. 1984. Electrical characteristics of the isolated dog ciliary body. Curr. Eye Res., 3: 417-421.

10. JACOB, T.J. and Civan, M.M. 1996. Role of ion channels in aqueous humor formation. Am. J. Physiol., 271 (3 Pt1): C703720.

11. Kishida, K., Sasabe, T., Iizuka, S., Manabe, R., and Otori, T. 1982. Sodium and chloride transport across the isolated rabbit ciliary body. Curr. Eye Res., 2(3): 149-152.
12. Krupin, T., Reinach, P.S., Candia, O.A., and Podos, S.M. 1984. Transepithelial electrical measurements on the isolated rabbit iris-ciliary body. Exp. Eye Res., 38: 115-123.

13. Watson, D.G., Ipbal, Z., Midgley, J.M., Pryce-Jones, H., Morrison, L., Dutton, G.N., Karditsas, S., and Wilson, W. 1993. Measurement of ascorbic acid in human aqueous humour and plasma and bovine aqueous humour by high-performance liquid chromatography with electrochemical detection. $J$. Pharm. Biomed. Anal., 11(4-5): 389-392.

14. Wiederholt, M. and ZADUNAISKY, J.A. 1987. Effects of ouabain and furosemide on transepithelial electrical parameters of the isolated shark ciliary epithelium. Invest. Ophthalmol. Vis. Sci., 28: 1353-1356.

(Received for publication, May 11, 1998

and in revised form, July 26, 1998) 